\title{
Emotions and feelings evoked in nursing students exposed to bullying behaviors in clinical settings
}

\author{
Dawna E. Rutherford; Carolyn R. Smith, Scott Bresler, Gordon L. Gillespie \\ University of Cincinnati, United States
}

Received: May 11, 2020

Accepted: July 13, 2020

Online Published: July 26, 2020

DOI: $10.5430 /$ jnep.v10n11p54

URL: https://doi.org/10.5430/jnep.v10n11p54

\begin{abstract}
Background and objective: Though not fully integrated into the profession, student nurses have been exposed to and experienced bullying behaviors with limited skills to mitigate the effects of the behaviors. This qualitative study analyzed the emotions evoked due to exposure to bullying behaviors. Desired to address the question: "How do student nurses feel when they are the recipient of bullying-type behaviors?"

Methods: DESIGN: Qualitative descriptive design. SETTING: A nursing college at an urban university in the Midwestern United States; PARTICIPANTS: Matriculated students enrolled in a pre-licensure nursing program. METHODS: As part of a larger mixed informed pilot study, each participant was assigned to either the control or intervention group. Participants in the intervention group received an educational intervention focused on bullying two weeks prior to a scheduled clinical simulation. Participants in both groups each completed an individual clinical simulation during which they were exposed to bullying-type behaviors meant to replicate behaviors they may encounter in actual clinical settings. All participants were informed of their right to disenroll from the study at any point. For the health and safety of participants, individuals were provided with safeguards during the study as well as upon conclusion of their participation. Immediately following the simulation, participants completed an individual debrief interview during which they were asked to describe how the simulation made them feel. Responses were audio recorded and transcribed verbatim. Data were analyzed using a descriptive qualitative to generate thematic results.

Results: The three major themes developed included Past Bullying-like Behavior, Feelings Experienced during Simulation, and Perceptions of the Simulation. Participants reported experiencing negative emotions due to the bullying behavior exposure despite receiving an educational intervention. Harmful emotions, such as sadness, led participants to question their ability to perform simple tasks. Student nurses possess the skills and knowledge to perform routine tasks; however, when bullying behaviors target nursing students, the negative behaviors have the potential to adversely affect the whole student.

Conclusions: Further research is warranted to identify programs to aid students in overcoming the negative bullying behaviors in the clinical setting.
\end{abstract}

Key Words: Nurse bullying, Horizontal violence, Lateral violence, Student nurses

\section{INTRODUCTION}

For over three decades researchers have been analyzing the pervasive problem of bullying behaviors in the nursing profession. ${ }^{[1]}$ Though viewed as a highly respectable and honorable profession to those outside of nursing, ${ }^{[2]}$ the continued presence of bullying behaviors among nurses is anything but respectable and honorable. Bullying behaviors are detrimental to nurses as well as those aspiring to become members of the largest healthcare profession in the United States. ${ }^{[3]}$ As a critical part of the healthcare industry, the need to combat bul-

*Correspondence: Dawna E. Rutherford; Email: rutherda@mail.uc.edu; Address: University of Cincinnati, United States. 
lying in the nursing profession is of great importance. Healthcare agencies such as the Joint Commission and American Nurses Association have published bulletins condemning such behavior and acknowledging bullying as a significant threat to safety in the healthcare arena. ${ }^{[4,5]}$

Although researchers have analyzed various aspects of bullying behaviors in the profession, few studies exclusively examine the effects of bullying behaviors upon pre-licensure students. Nursing students, though not licensed to work to the full capacity of registered nurses, unfortunately have been introduced to bullying behaviors in the profession. To intervene and prevent irreparable harm to the next generation of nurses, researchers are seeking to understand the bullying phenomenon in the student nurse population and find ways to mitigate the potential effects of exposure to bullying behavior until the problem has been eradicated.

\subsection{Bullying behaviors in nursing}

The verb "bully" is synonymous with other actions such as oppress, torment, or intimidate. ${ }^{[6]}$ Bullying actions describe behaviors occurring at all levels within the nursing profession. In some instances, an individual nurse may experience an episodic incident of bullying behavior. However, if the same individual was targeted and endured the same negative behaviors over a period of six months or longer, researchers indicated the culmination of actions constitutes bullying. ${ }^{[7]}$

It should be noted researchers analyzing workplace bullying and bullying behaviors in nursing use terms such as incivility, ${ }^{[8,9]}$ lateral violence, ${ }^{[10,11]}$ horizontal violence ${ }^{[12]}$ in addition to or instead of bullying based upon how the construct is defined. Hershcovis ${ }^{[13]}$ noted "workplace incivility is defined as a low intensity behavior with ambiguous intent, while workplace bullying is assumed to have high intensity and intent" though the victim may perceive the intension and intensity of the negative act differently. That is, "although the incivility measure purports to ask about low intensity behaviors, the items may or may not be of low intensity from the perspective of the victim."

There are also several terms describing a cluster of similar negative behaviors such as humiliation, criticism often targeted towards a subordinate individual that encompass the act of bullying. ${ }^{[14]}$ Regardless of the terminology used, the negative behaviors can have a grave impact upon the targeted individual and have the potential to inflict harm and fear upon the targeted individual. ${ }^{[15]}$ For consistency and clarity throughout the current paper, the terms bullying and bullying behaviors are used.

\subsection{Prevalence}

Researchers have annotated the existence of bullying-type behaviors within the nursing profession for several decades. Unfortunately, at the beginning of their nursing journey, nursing students throughout the world have been targets of these negative behaviors perpetrated by a host of individuals. Bowllan ${ }^{[16]}$ reported the percentages of nursing students who experienced some form of bullying or bullying behaviors ranged from $44.7 \%$ to $95.6 \%$. Recently, Birks, Budden, Biedermann, Park, and Chapman ${ }^{[17]}$ noted there still were variations in the number of student nurses who experienced bullying behaviors. For example, in a Turkish study involving 202 student nurses, researchers discovered the frequency of bullying experienced by student nurses was slightly over $78 \% .{ }^{[18]}$ Other findings noted $40 \%$ of nursing students experienced some form of bullying and over $57 \%$ of the nursing student study participants observed bullying. ${ }^{[19]}$ The discrepancy in the number of instances of bullying may vary due to underreporting of the behaviors resulting from fear of reprisal or being shunned. ${ }^{[7,19]}$ Although the student nurse population comprise a small subset of nursing individuals exposed to bullying in clinical settings, researchers are discovering the need to analyze the impact negative behaviors such as bullying may have on this population. Scientists acknowledge student nurses are adversely affected by bullying behaviors; ${ }^{[20]}$ however, there is limited research revealing the emotions evoked from experiencing bullying behaviors.

Identifying the emotions evoked when bullying behaviors are experienced will further assist researchers in addressing bullying in the nursing profession. This would allow future researchers to develop skills for nursing students and professional nurses to successfully process the negative emotions caused by experiencing bullying behaviors. Hence, the purpose of this study was to describe the emotions and feelings elicited in student nurses from experiencing bullying behaviors. The research question which guided this study was the following: How do student nurses feel when they are the recipient of bullying-type behaviors?

\section{METHODS}

This article reports the results of the qualitative phase of a pilot mixed informed study, which used a concurrent quantitative dominant design. The overall purpose of the mixed informed study was to examine the feasibility of an educational intervention to mitigate the effect of bullying type behaviors on the student nurses' clinical performance. Whereas the quantitative phase used a quasi-experimental design to examine feasibility of the intervention, a descriptive qualitative design was applied to explore emotions evoked in nursing students when they experience bullying-type behaviors in a 
clinical setting.

\subsection{Recruitment and study setting}

The study took place at one urban midwestern university's college of nursing. Students enrolled in one of two prelicensure nursing programs, traditional BSN and accelerated direct-entry MSN, were invited to participate. To be eligible, students must be fully matriculated, have completed the fundamentals of nursing course, and be 18 years or older. Using a convenience sampling approach, participant recruitment included distributing study information via electronic mail, posting recruitment flyers in the college building, and conducting brief in-person information sessions in classes attended by the target population. Students interested in study participation received instructions to contact the Principal Investigator (PI) to determine eligibility and enroll in the study.

\subsection{Procedures}

The university's institutional review board (IRB) reviewed and approved the study. Prior to proceeding with the study activities, written informed consent was obtained from each participant. The PI discussed with each study participant how data would be kept confidential and the right to leave the study at any point. Distractions introduced to participants during the simulation were intentionally designed to replicate those typically experienced in clinical settings. Promotion of study participant safety included informing participants of the following: 1) the right to leave the study at any point; 2) how each simulation and participant would be monitored by the PI, a registered nurse, for signs of discomfort and distress; and 3) in the event that a participant would require counseling services due to study participation, the PI and co-PI would help the participant access counseling services. In addition, participants were informed that study participation would have no influence or impact on grades in their current nursing classes. Each participant received payment to compensate for their time and effort. Data were collected from December 2018 until July 2019.

Upon enrollment, participants were randomly assigned to one of three distinct study arms. All study participants were asked to participate in a high-fidelity simulation where the task of medication administration would be performed. While completing medication administration simulation, all participants were exposed to distractions that were either non-bullying or bullying in nature. Participants were scheduled one at a time to participate in the simulation. All participants were informed they could leave the simulation at any time and were provided a safe word to use ("timeout") if they wanted the simulation to stop. The steps mentioned above allowed for the participants to be safe during the study yet permitted data collection to occur.

Standardized participants (i.e. professional actors) were hired to portray the role of a charge nurse and instructed to distract the participant by introducing non-bullying and bullying behaviors during the simulation. Bullying behaviors included use of negative body language such as eye rolling, crossed arms, pacing the floor in conjunction with verbal attacks directed towards the participants while they performed the medication administration. Moreover, the standardized participants were given instructions to be unhelpful and provided with scripted negative phrases to say to study participants (e.g., "I don't know why I'm here. She knows I hate student nurses" or "You're kinda slow [giving that medication]. I don't know how you'll ever make it [as a registered nurse].”)

Once the simulation was complete, all participants completed a debrief interview to discuss their perceptions of the simulation. These interviews were audio-recorded and transcribed verbatim. Interview data were analyzed using descriptive content analysis to explore for feelings evoked in nursing students when exposed to bullying behavior. ${ }^{[21,22]}$ Steps used to conduct the data analysis included the following:

1) The research team members started the analysis by independently reading each transcript line by line. The purpose of performing this task was to gain an overall understanding of the data. Each researcher reviewed the transcripts numerous times to understand the essence of the information.

2) Once the data had been reviewed, each research team member sought out salient themes that were observed.

3) Next the team met together to discuss their findings based upon the initial review of the data and collaboratively develop codes.

4) Then the team members independently completed line by line coding of the data.

5) The team met again to review, compare, and discuss their line by line coding. Discrepancies were discussed until consensus was achieved.

6) Upon consensus, the team collaboratively developed themes represented by the codes and sought out statements that best reflected the themes observed.

To establish trustworthiness of this study, the beforementioned steps were taken. Based on guidance from Guba and Lincoln, ${ }^{[23]}$ key aspects of were integrated throughout the study. To ensure credibility of the research, the participants' responses were recorded, and their words were transcribed verbatim allowing the investigators to capture the true essence of the experiences during data analysis. Dependability was enhanced via the use of triangulation. The 
process revealed themes in which the PI and co-PI first independently evaluated the data then compared and came to a consensus regarding coding decisions. As an assurance the data were collected from the desired population of interest and an assurance of transferability of the study, consistent steps were followed to recruit from student nurses, the specific population of interest. For confirmability or manner to ensure confidence results could be substantiated by other investigators, bi-weekly to monthly meetings with the co-PI were implemented to guide the interpretation of the study.

\section{RESUltS}

Ten participants completed the debrief interview which immediately followed the simulation experience. The sample was predominately female (90\%), Caucasian (90\%), and $70 \%$ from the traditional undergraduate BSN program. On average, participants were 23.1 years old (SD 4.2) with participants ranging in age from 20 to 34 years old. Referring back to the research question, "How do student nurses feel when they are the recipient of bullying-type behaviors?", three themes were generated from the data focused on participants' emotional responses to bullying-type behaviors in a clinical setting. Themes which emerged were linked to the following: the bullying-type behaviors the participants reported encountering in a clinical setting previously, feelings elicited specific to the bullying-type behavior in the simulation, and feelings elicited as a result of the bullying interfering with the task subjects were trying to complete. To explore the salient themes, they have been separated and entitled as the following: My Experience of Past Bullying-like Behavior Informs My Current Feelings, My Immediate Feelings About Experiencing Bullying Behaviors, and Feelings Associated with Reflecting on the Simulation Experience Each theme will be described along with its exemplar quotes from participants.

\subsection{Theme One: My experience of past bullying-like be- havior informs my current feelings}

The first theme focuses on how the types of bullying-like behaviors the nursing students had either directly experienced or witnessed in a clinical setting informed their emotional response to the simulation. These experiences occurred during a clinical rotation in nursing school or their paid position in a healthcare setting (e.g., patient care assistant, patient care technician). Bullying-like behaviors described included rude behaviors, which where the most common category of bullying behaviors students reported witnessing or experiencing.

The participants also discussed incidents of verbal abuse, another common type of bullying behavior observed or experienced. Participants noted nurses harshly speaking about

Published by Sciedu Press other colleagues without the individual present as well as directly to their co-worker. A study participant recounted a verbally abusive incident directly involving another student yet observed during their first clinical rotation:

... Like, I remember one person, one student forgot to report a blood pressure before they were being discharged, and she, like, yelled at her in front of the patient, and everybody on the floor, and stuff. And it was, like, kind of weird.

Distinct from verbal abuse, a person's rude actions or demeanor can impact surrounding individuals. Participants reported experiencing and witnessing rude behaviors from nurses and patients in the clinical setting. They described the coldness of a nurse's stare or lack of compassion shown towards current and future nurse colleagues. Rude behavior by clinical nurses left some participants questioning the role of a professional nurse. For example, one participant recalled her experience:

Yeah, definitely. Um, I would say, even, like, my last clinical I was - yeah, I observed some nurses, kind of, being rude to one another behind their back, or even to the students... Um, a lot of the nurses, I'll say with my peers, like, 'Why don't they want us here? We're here to learn. We're here to, like, take your place when you're older.' You know? It's like, this is what this profession is. It's learning. So, you might as well help each other. They definitely, sometimes, nurses don't like having students there. Just because we can't do a lot doesn't mean we shouldn't be there because that's how we're gonna learn.

Despite being viewed as unprofessional, rude bullying-like behaviors of nurses were also not unexpected. A participant reported witnessing a variety of nurses at her workplace engaged in bullying-like behavior:

And it just all depends on the nurse you get because sometimes they're, kind of, like that. Um... They... are a little bit, um, demeaning, almost. Because they're busy too, and they want to get to everything, which makes sense. Um, and then, mostly I've heard it, like, behind other nurses' backs, though. Like, nurses to other nurses talking about either a nurse, or a PCA [patient care assistant], or someone behind their back. And as a PCA, I just stand there and, like, listen because they don't think I, like - they don't consider me, like, an issue in that. 


\subsection{Theme two: My immediate feelings about experienc- ing bullying behaviors}

The second theme focuses on the feelings participants reported experiencing while engaged in the simulation. Often the words "feelings" and "emotions" have been used interchangeably and synonymously; however, some researchers disagree with that approach. For humans to express their feelings, they would often experience an emotion, a primal reaction to an outside event. ${ }^{[24]}$ Feelings are a mental outgrowth of the emotions an individual may experience; therefore, feelings though closely related are not the same as emotions. ${ }^{[25]}$

To assist in identifying the feelings experienced by the participants, a Feeling Wheel, developed by Gloria Willcox was used. Designed to assist individuals with identifying and expressing their feelings, the Feelings Wheel contains an inner circle with the six primary feelings humans experience (sad, mad, joyful, powerful, peaceful, and scared) and two distinct outer circles containing secondary feelings (i.e. variants of the primary feelings). ${ }^{[26]}$ Primary feelings reflected in participants' responses were Mad, Sad, and Scared. For example, one participant reflected on how they felt during the simulation:

Um, it made me feel bad about myself, and like, my competency, like, just knowing, like, someone doesn't think I'm doing a good job, or like that. However, especially, I think, um, the university like classes have really taught us that not everyone is going to be nice to you, and that it's really important just to keep a professional face, and make sure you just talk to them, especially in front of the patient just professionally, making sure, like, you don't get all worked up because then you will make more mistakes. Just try to keep your cool, which I try to, but as soon as... but on the inside, I was like, oh man.

There were also a few participants who expressed feeling a degree of empowerment because of the simulation. Being a part of the simulation gave them a chance to practice dealing with a real-life situation of bullying. For example, it allowed one participant to consider what he would do in similar situations in the future:

I definitely didn't want to get too much into it in front of the patient - which is never a good idea, but probably in real-life scenario, I would probably be like "hey, you know, I'm done with this. Hey, let me - let me talk to you in a second."

\subsection{Theme three: Feelings associated with reflecting on the simulation experience}

The final theme identified focused on the perceptions or feelings regarding the simulation. Student participants were asked two open-ended questions about the simulation: What went well? and What did not go well? The participants were able to elaborate about their experience. Using the Feeling Wheel to explore primary feelings regarding the simulation, the key feeling expressed from the participants was feeling scared. Although the participants routinely administer medications in the clinical setting, the scenario introduced with the administration of a solitary medication provoked this primary feeling.

Hmm... Maybe just focus on, like, what I was doing. Kind of tune out what he was saying, and so, like, it wouldn't get in my head as much...

Yeah, it just felt like someone was, like, saying, like, I was distracted in what he was saying, and how he was judging me than what I should have just been like, doing, and like focusing on the patient. And then the patient, you could, like, seem like the patient could kind of tell because he was like, "Oh, is everything okay?" Because they probably felt uncomfortable, as well.

\section{Discussion}

Previous researchers noted the adverse effects bullying and bullying behaviors pose to the victims within the student nurse population. Bullying behaviors allow the recipient (student nurse) to perceive a lack of power or control within the clinical setting contributing to undo stress. ${ }^{[16,27]}$ Development of negative self-image as well as the perception being devalued as a novice healthcare participant were commonalities reported in previous studies and noted in this study. ${ }^{[16,17]}$ Additional comments made by participants illuminated other findings. The challenges student nurses have managing bullying behaviors and not being surprised by the presence of bullying behaviors/negative distractions in the clinical settings warranted additional examination.

\subsection{Power and powerlessness}

Gaventa's Theory of Power and Powerlessness ${ }^{[28]}$ assisted provides a rationale for the data obtained and what has been observed in the profession of nursing. Gaventa's argument noted there are three levels of power and individuals have the potential to progress through the levels in order to achieve a more equitable division of power. Those that do not progress through the levels of power, simply acquiesce and do not confront the perpetrators of the negative behavior as was 
noted in the study participants. Historically within the nursing profession, there have been perceived power imbalances. Student nurses and their unique role in the healthcare historically are instructed on nursing social norms which often includes the introduction to a system where students have the potential to be oppressed hence the perceived lack power they have. Perceived powerlessness has the potential to impact the individual negatively.

\subsection{Difficult to confront nurses as students}

As a nursing student, the feeling of being scared could be aroused by new clinical experiences allowing for growth into a professional nurse. Yet an encounter with bullying or bullying behavior may lead to an altered self-perception of the targeted student. An undercurrent of being scared because of bullying behaviors, affects the care a student nurse delivers as well as his or her ability to cope with the challenging individual. Even though over half of the participants $(60 \%)$ received bullying information, only one participant felt comfortable and self-assured to confront a perpetrator of bullying behaviors and identifying the behaviors by name. Participants verbalized not knowing what to do.

The duration of the intervention may not be enough to make an appreciable change in a nursing student's knowledge of and ability to confront bullying behavior. Smith, Gillespie, Brown, and Grubb ${ }^{[18]}$ suggested providing students with knowledge and skills to counter bullying behaviors throughout the duration of their nursing education. As with any necessary skills, information regarding bullying potentially could be provided throughout curriculum allowing for time to rehearse and integrate skills and knowledge.

\subsection{More permissible from patients}

Though healthcare professions can prove to be challenging, bullying behaviors should not be tolerated from nursing and medical professionals nor clients of the healthcare settings. Patients are also known as a source of negative behaviors targeting nursing students. ${ }^{[16,26]}$ Participants of the study noted the negative feelings as a result of experiencing bullying behavior or observing it. Despite the feelings triggered, some participants rationalized and were willing to excuse behaviors perpetrated by patients noting the patients' illnesses or fatigue as possible contributors to actions displayed. Student nurses need to have a better understanding regarding acceptable and unacceptable behaviors. Even in the event the patient were ill, abusive behaviors should not be condoned.

\subsection{Limitations}

Within this study there were several limitations including small sample size and no member checking of qualitative results. Though multiple recruitment plans were implemented, and two pre-licensure programs were included, there were limited volunteers for the study. As a result of the sample size $(n=10)$, researchers were limited in obtaining saturation and prevented from further exploration of differences among groups based upon gender, race, and age. Though the research members independently reviewed the data before coming to a consensus of what the participants revealed, confirmation of results with study participants was not performed.

\subsection{Implications for nursing profession}

The American Nurses Association noted any unprofessional behavior including but not only, any form of harassment or threatening behavior is against the code of ethics for nursing. ${ }^{[5]}$ The Joint Commission acknowledged any negative behavior, including bullying behaviors, threatens the safety of patients in the healthcare system. ${ }^{[4]}$ With the nursing profession recognized as a well-respected and caring profes$\operatorname{sion}^{[2]}$ as well as two professional organizations condoning bullying behaviors, these negative acts should never occur. It is imperative nursing students are not being harmed while in the clinical setting nor are the patients under their watch. Student nurses are prepared throughout their didactic education to perform cognitive clinical tasks prior to entering the clinical setting, yet they are woefully lacking in knowledge and skills for the potential emotional toll of bullying behaviors.

Student nurses when in the clinical setting are not fully integrated members of the healthcare team but within a short time, they will be. As novice healthcare members, student nurses need to learn professional behaviors in addition to evidence based nursing care. Until bullying and bullying behaviors are eradicated, they remain an unfortunate part of nursing and student nurses need to be aware of bullying behaviors and how to manage them is vital.

\subsection{Implications for research}

Though some participants in this and other studies expressed negative feelings as a result of experiencing bullying behaviors, it is unknown what the long-term effects of the negative experience has had upon the individual. Did the repeated exposure to bullying behaviors in the clinical setting cause a person to become more resilient or did the exposure disrupt their overall being and how they developed as a novice nurse.

With nursing students being the future of the nursing profession, students and licensed nurses need information regarding bullying behaviors presented similarly. As a means of preparing for the profession rather than inciting fear, all nurses need a rudimentary understanding of what bullying behaviors are as well as the potential detriment. Whether acquired 
skills of experienced nurses compared to skills of student nurses affect the breath of bullying education needed can be determined with additional research.

Various means to recruit students into the study were used yet a limited number of participants agreed to participate. To gain a greater understanding of the effects of bullying behaviors on the student nurse population, future researchers can seek a large heterogeneous sample. By having an ample heterogenous sample, additional knowledge regarding whether variables such as the students' age, gender, or race interact with bullying behaviors upon an individual and would allow for a more complete understanding of bullying behaviors and how to introduce an effective intervention.

\section{Conclusion}

Student nurses are future healthcare professionals soon to be entrusted with the care of ailing individuals. Though not fully integrated into the profession of nursing, students are exposed to and experience unprofessional conduct such as bullying behaviors. Rather than eagerness to provide care to those in need, bullying behaviors allow students to experience trepidation prior to entering a respected profession. In depth education regarding bullying behaviors needs to be presented to assist in managing the negative effects of such behaviors.

\section{ACKNOWLedgements}

This project was partially supported by the Jonas Nurse Scholar Program and the National Institute for Occupational Safety and Health through the Pilot Research Project Training Program of the University of Cincinnati Education and Research Center Grant \#T42OH008432.

\section{CONFlicts OF INTEREST Disclosure}

The contents are solely the responsibility of the authors and do not necessarily represent the official view of Jonas Philanthropies nor the National Institute for Occupational Safety and Health. Authors deny any conflicts of interest.

\section{REFERENCES}

[1] Randle J. Bullying in the nursing profession. J Adv Nurs. 2003 Aug; 43(4): 395-401. PMid:12887358 https ://doi.org/10.1046/j. 1365-2648.2003.02728. $\mathrm{x}$

[2] Gallup (2018, December). Nurses again outpace other professions for honesty, ethics. [Internet]. United States: Gallup News; c2018-2019 [cited 2019 December 18]. Available from: https://news.gallup.com/poll/245597/nurses-aga in-outpace-professions-honesty-ethics.aspx

[3] News and Information-Fact Sheet-Nursing Fact Sheet [Internet]. Washington D.C.: American Association of Colleges of Nursing; c2019 [cited Dec 18]. Available from: https://www.aacnnursing.org/News-Information/FactSheets/Nursing-Fact-Sheet

[4] The Joint Commission Quick Safety Issue 24 [Internet]. Oakbrook Terrace: The Joint Commission; c2015-2016 [cited 2019 Dec 18]. Available from: https://www.jointcommission.org/assets /1/23/Quick_Safety_Issue_24_June_2016.pdf

[5] ANA: American nurses association position statement on incivility, bullying, and workplace violence [Internet]. Silver Spring, MD: American Nurses Association; c 2015-2020 [cited 2020 January 10] Available from: https://www.nursingworld.org/ 49d6e3/ globalassets/practiceandpolicy/nursing-excellence/ incivility-bullying-and-workplace-violence--ana-p osition-statement.pdf/

[6] Merriam-Webster Definition of Bully [Internet]. Springfield, MA: Merriam-Webster; c 2019[cited 2019 August 13]. Available from: https://www.merriam-webster.com/dictionary/bully

[7] Einarsen S, Hoel H, Zapf D, et al. The concept of bullying at work: The European tradition. In: Einarsen S, Hoel H, Zapf D, Cooper CL, editors. Bullying and emotional abuse in the workplace. International perspectives in research and practice. London, England: Taylor and
Francis; 2011. p.3-30. https ://doi .org/10.1201/EBK1439804 896-3

[8] Blevins S. Impact of incivility in nursing. Medsurg Nurs. 2015 Nov; 24(6): 379 .

[9] De Villers MJ, Cohn T. Performance potential special: Incivility in nursing practice. Nurs Manage. 2017 Oct; 48(10): 42-51. PMid:28957831 https://doi.org/10.1097/01.NUMA.000052 2183.31780.76

[10] Griffin M. Teaching cognitive rehearsal as a shield for lateral violence: An intervention for newly licensed nurses. J Contin Educ Nurs. 2004 Nov; 35(6): 257-63. PMid:15584678 https : //doi .org/10 .3928/0022-0124-20041101-07

[11] Roberts SJ. Lateral violence in nursing: A review of the past three decades. Nurs Sci Q. 2015 Jan; 28(1): 36-41. PMid:25520463 https://doi.org/10.1177/0894318414558614

[12] Becher J, Visovsky C. Horizontal violence in nursing. Medsurg Nurs. 2012 Jul; 21(4): 210-3.

[13] Hershcovis MS. "Incivility, social undermining, bullying, oh my!": A call to reconcile constructs within workplace aggression research. J Organ Behav, 2011 Apr; 32(3): 499-519. https ://doi .org/10 $.1002 /$ job. 689

[14] Bartlett JE, Bartlett ME. Workplace bullying: an integrative literature review. Adv Dev Hum Resour. 2011 Feb; 13(1): 69-84. https://doi .org/10.1177/1523422311410651

[15] Rutherford DE, Gillespie GL, Smith CR. Interventions against bullying of prelicensure students and nursing professionals: An integrative review. Nurs Forum. 2019 Jan; 54(1): 84-90. PMid:30380142 https://doi.org/10.1111/nuf . 12301

[16] Bowllan NM. Nursing students' experience of bullying: Prevalence, impact, and interventions. Nurse Educ. 2015 Jul/Aug; 40(4): 194-8. PMid:25763780 https ://doi.org/10.1097/NNE. 0000000000 000146 
[17] Birks M, Budden LM, Biedermann N, et al. A 'rite of passage?': bullying experiences of nursing students in Australia. Collegian. 2018 Feb; 25(1): 45-50. https://doi.org/10.1016/j.colegn. 201 7.03 .005

[18] Karatas H, Ozturk C, Bektas M. A study of bullying against nursing students. J Nurs Res. 2017 Jun; 25(3): 198-202. PMid:28481815 https://doi.org/10.1097/JNR.0000000000000144

[19] Minton C, Birks M, Cant R, et al. New Zealand nursing students' experience of bullying/harassment while on clinical placement: A cross-sectional survey. Collegian. 2018 Dec; 25(6): 583-9. https : //doi.org/10.1016/j.colegn.2018.06.003

[20] Smith CR, Gillespie GL, Brown KC, et al. Seeing students squirm: Nursing students experiences of bullying behaviors during clinical rotations. J Nurs Educ. 2016 Sep; 55(9): 505-13. PMid:27560118 https://doi.org/10.3928/01484834-20160816-04

[21] Sandelowski M. Rigor or rigor mortis: The problem of rigor in qualitative research revisited. ANS Adv Nurs Sci. 2003 Dec; 16(2): 1-8. PMid:8311428 https://doi.org/10.1097/00012272-199 312000-00002

[22] Sandelowski M. Whatever happened to qualitative description? Res Nurs Health. 2000 Aug; 23(4): 334-340.
https://doi.org/10.1002/1098-240X(200008)23:4<334::AIDNUR9>3.0.CO;2-G

[23] Guba E, Lincoln Y. Epistemological and methodological bases of naturalistic inquiry. Educational Communication and Technology: A Journal of Theory, Research, and Development. 1982 Dec; 30(4): 233-52.

[24] Lenzen M. Feeling our emotions( 2005, April). Sci Am Mind [Internet]. 2005 April; 16(1). https://doi.org/10.1038/scientif icamericanmind0405-24

[25] Pace-Schott EF, Amole MC, Aue T, et al. Physiological feelings. Neurosci Biobehav Rev. 2019 Aug; 103: 267-304. PMid:31125635 https://doi.org/10.1016/j.neubiorev.2019.05.002

[26] Willcox G. The feeling wheel: A tool for expanding awareness of emotions and increasing spontaneity and intimacy. Transactional Analysis Journal. 1982 Oct; 12(4): 274-6. https ://doi.org/10 $.1177 / 036215378201200411$

[27] Magnavita N, Heponiemi T. Workplace violence against nursing students and nurses: An Italian experience. J Nurs Scholarsh. 2011 Jun; 43(2): 203-10. PMid:21605325 https://doi.org/10.1111/ j.1547-5069.2011.01392.x

[28] Gaventa J. Power and powerlessness: Quiescence and rebellion in an Appalachian Valley. Urbana: Universityof Illinois Press; 1980. 